\title{
Structural and Mechanical Properties of Zr-Si-N Thin Films Prepared by Reactive Magnetron Sputtering
}

\author{
Flávio Gustavo Ribeiro Freitas ${ }^{a *}$, Roberto Hübler ${ }^{b}$, Gabriel Soares ${ }^{c}$, \\ Amanda Gardênia Santos Conceição ${ }^{a}$, Edson Reis Vitória ${ }^{a}$, Renata Gomes Carvalho ${ }^{a}$,
}

Eduardo Kirinus Tentardini ${ }^{a}$

\begin{abstract}
${ }^{a}$ Departamento de Ciência e Engenharia de Materiais, Universidade Federal de Sergipe - UFS, Avenida Marechal Rondon, s/n, CEP 49100-000, São Cristóvão, SE, Brazil

${ }^{b}$ Instituto de Física - GEPSI, Pontifícia Universidade Católica do Rio Grande do Sul - PUCRS, Avenida Ipiranga, 6681, CEP 90619-900, Porto Alegre, RS, Brazil

'Instituto de Física, Universidade Federal do Rio Grande do Sul - UFRGS, Avenida Paulo Gama, 110, CEP 90040-060, Porto Alegre, RS, Brazil
\end{abstract}

Received: October 24, 2014; Revised: June 16, 2015

\begin{abstract}
Zirconium silicon nitride $(\mathrm{ZrSiN})$ thin films were deposited by reactive magnetron sputtering in order to verify the silicon influence on coating morphology and mechanical properties. $\mathrm{The} \mathrm{Si} /(\mathrm{Zr}+\mathrm{Si})$ ratio was adjusted between 0 to $15 \%$ just modifying the power applied on the silicon target. Only peaks associated to $\mathrm{ZrN}$ crystalline structure were observed in XRD analysis, since $\mathrm{Si}_{3} \mathrm{~N}_{4}$ phase was amorphous. All samples have (111) preferred orientation, but there is a peak intensity reduction and a broadening increase for the sample with the highest $\mathrm{Si} /(\mathrm{Zr}+\mathrm{Si})$ ratio $(15 \%)$, demonstrating a considerable loss of crystallinity or grain size reduction (about $8 \mathrm{~nm}$ calculated by Scherrer). It was also observed that the I(200)/I(111) ratio increases with silicon addition. Chemical composition and thickness of the coatings were determined by RBS analysis. No significant changes in nanohardness with increasing $\mathrm{Si}$ content were found. The morphology observed by FEG-SEM presents non columnar characteristics for thin films with silicon addition. The set of results suggests that $\mathrm{Si}$ addition is restricting the columnar growth of $\mathrm{ZrN}$ thin films. This conclusion is justified by the fact that $\mathrm{Si}$ contributes to increase the $\mathrm{ZrN}$ grains nucleation during the sputtering process.
\end{abstract}

Keywords: thin films, ZrSiN, magnetron sputtering, nanohardness, RBS

\section{Introduction}

Nitride transition metal thin films have been used in the last decades due to properties as hardness and wear resistance ${ }^{1-3}$. Zirconium nitride $(\mathrm{ZrN})$ is a typical coating used because its tribological properties, besides corrosion and oxidation resistance. Even with differentiated properties, $\mathrm{ZrN}$ thin films present columnar microstructure, micro-cracks and pores, which are defects associated with transition metals nitrides deposited by PVD and CVD techniques. These coatings characteristics allow direct contact between the external environment and the substrate, compromising the mechanical properties and its applications in high temperature or corrosive environments ${ }^{4-6}$.

It is important to note that $\mathrm{ZrN}$ thin films mechanical properties are associated with a complex state of compression of the crystalline lattice (residual stress). The deposition process is usually carried out at low temperatures $\left(\mathrm{T}<300^{\circ} \mathrm{C}\right)$ inhibiting $\mathrm{ZrN}$ molecules to achieve its equilibrium state in the lattice structure. The result is that the crystalline lattice remains in a metastable condition and, consequently, the structure can be changed if the necessary activation energy is provided to the system, resulting in degradation of coatings properties $^{7-9}$.

An alternative to modify $\mathrm{ZrN}$ thin films microstructure and morphology is the addition of a third element as silicon. The Si addition promotes a two phase microstructure formation: a crystalline $(\mathrm{ZrN})$ and an amorphous phase $\left(\mathrm{Si}_{3} \mathrm{~N}_{4}\right)$. The amorphous phase is located at the grain boundaries and contributes to reduce the $\mathrm{ZrN}$ grain size, since it increases the $\mathrm{ZrN}$ grains nucleation rate. The final grain size is less than $10 \mathrm{~nm}$, resulting in the formation of a nanocomposite structure. These characteristics have potential to change thin film morphology and macroscopic properties ${ }^{10-12}$.

This type of microstructure is dense, homogeneous and not significantly affected by diffusion activated processes, which means that it has a high thermal stability ${ }^{13-17}$. But, properties and microstructure of $\mathrm{ZrSiN}$ thin films are function of silicon concentration and deposition techniques (PVD or CVD) parameters. So, although many studies demonstrate the advantages of adding silicon to nitride thin films, there are gaps and discussions about microstructure formation and influence of Si content and deposition parameters on coatings physical and chemical properties ${ }^{2,3,7-17}$. 
The study proposal was to deposit thin films of $\mathrm{ZrSiN}$ system by reactive magnetron sputtering (RMS) varying the Si concentration in each coating. Grazing Angle X-ray diffraction (GAXRD), Field Emission Scanning Electron Microscopy (FEG-SEM), Rutherford Backscattering Spectroscopy (RBS) and nanohardness techniques were used to analyze coatings morphology and mechanical properties.

\section{Material and Methods}

Thin films used in this work were co-deposited by reactive magnetron sputtering with an AJA Orion 5-HV Sputtering Systems model with two independents targets, $\mathrm{Zr}$ and $\mathrm{Si}$, with purity of 99.7 at $\%$ and 99.5 at \%, respectively. Before deposition, substrates were underwent ultrasonic cleaning in acetone during 30 minutes, washed with ethyl alcohol (54 $)$ and then dried. The chamber was preconditioned to a base pressure of $1 \times 10^{-7}$ Torr and targets were bombarded ionically to remove oxide layers from the surface before deposition.

All deposition parameters were maintained constant during depositions except the power used at silicon target, as showed in Table 1. The distance target-substrate applied in all depositions was $120 \mathrm{~mm}$ and two different types of substrates were used according to the characterization technique: silicon wafer for GAXRD, nanohardness and FEG-SEM analysis and polyethylene plates for RBS studies. The thickness and deposition time was also adjusted to comply with the required analysis, $50 \mathrm{~nm}$ and 12 minutes for RBS samples, $300 \mathrm{~nm}$ and 60 minutes for FEG-SEM and GAXRD samples and $600 \mathrm{~nm}$ and 120 minutes for nanohardness samples. No external heating was applied to the substrates.

GAXRD patterns were performed on a Shimadzu XRD-6000 model $(\mathrm{Cu}-\mathrm{K} \alpha$ radiation; $\lambda=1.54 \AA)$ with grazing angle of $1^{\circ}$. The morphology of the film cross section was observed on a high-resolution FEG-SEM JSM-6330F.

Nanohardness analyses were performed in a Fisherscope HV 100 with a Berkovich indenter and indentation depth of $40 \mathrm{~nm}$. This technique also permits to determine the films Young's modulus. RBS analysis were performed using a $3 \mathrm{MV}$ tandetron with alpha particles accelerated up to $2 \mathrm{MeV}$, with a silicon based detector at an angle of $165^{\circ}$ and resolution of $12 \mathrm{keV}$.

\section{Results and Discussion}

Stoichiometric zirconium nitride thin films has a metallic gold color ${ }^{18}$ and the $\mathrm{ZrN}$ coating deposited in this work with $\mathrm{Ar} / \mathrm{N}_{2}$ ratio of $19 / 2$ presented this characteristic. A set of $\mathrm{ZrSiN}$ thin films modifying Si concentration were deposited using different powers applied on the silicon target. These samples were analyzed by RBS technique to measure coatings thickness, identify chemical elements and their respective concentrations. All samples present similar results, except the silicon peak, which is function of the power applied to the Si target. For this reason it is presented in Figure 1 just the RBS analysis for sample $\mathrm{ZrSiN} 3$.

Analyzing Figure 1 is possible to identify the presence of $\mathrm{Hf}, \mathrm{Zr}, \mathrm{Si}, \mathrm{N}$ and $\mathrm{O}$ from thin film and $\mathrm{C}$ from substrate and these chemical elements were detected for all samples. The hafnium presence is due the contamination of this chemical element on $\mathrm{Zr}$ target, once by manufacturer data the target is $99.7 \% \mathrm{Zr}$ and $0.3 \%$ Hf. RBS results also show that the films are near the stoichiometric concentration, confirming the $\mathrm{Ar} / \mathrm{N}_{2}$ ratio of $19 / 2$. The areal densities of zirconium and nitrogen chemical species were determined using a Sb implanted silicon standard.

Table 2 shows $\mathrm{Zr}, \mathrm{N}$ and $\mathrm{Si}$ concentration in at.\% and $\mathrm{Si} /(\mathrm{Zr}+\mathrm{Si})$ ratio determined by $\mathrm{RBS}$ for all samples. The coatings $\mathrm{Si} /(\mathrm{Zr}+\mathrm{Si})$ ratio were characterized as low $(6.2 \%)$, intermediary (8.0\%) and high (15.0\%), for sample ZrSiN_1, ZrSiN_2 and ZrSiN_3, respectively. The coatings thickness was estimated in approximately $60 \mathrm{~nm}$ for all samples.

Figure 2 shows the GAXRD analysis for all samples. The ZrN, ZrSiN_1 and ZrSiN_2 XRD patterns are almost identical, but the ZrSiN_3 has a peak intensity reduction and a small increase in (111) peak width, demonstrating a considerable loss of crystallinity or grain size reduction. $\mathrm{Si}_{3} \mathrm{~N}_{4}$ structure is amorphous (confirmed by GAXRD analysis) and its presence causes the reduction of diffraction peaks intensity. $\mathrm{Si}_{3} \mathrm{~N}_{4}$ particles contribute to $\mathrm{ZrN}$ grain nucleation process during film growth, resulting in a structure with reduced grain size ${ }^{10,19}$. The crystallite size calculated by Scherrer for $\mathrm{ZrSiN} 3$ is about $8 \mathrm{~nm}$ (nanocomposite structure), while

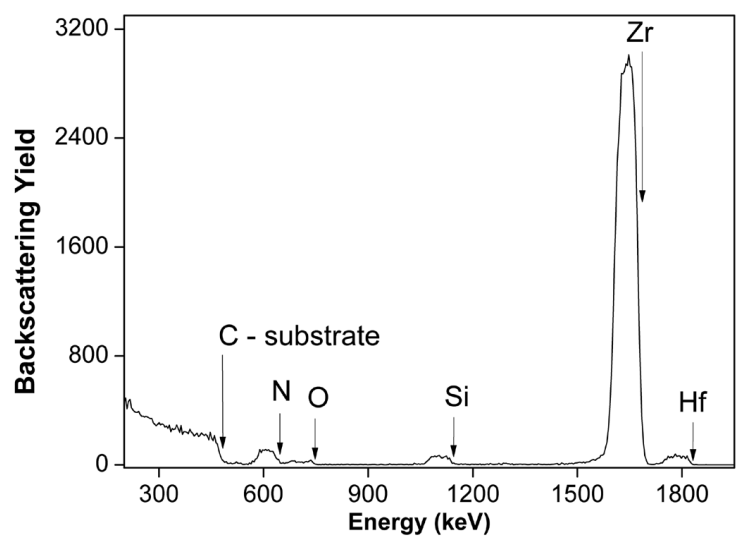

Figure 1. RBS analysis for sample $\mathrm{ZrSiN}$ 3. Coatings compositions are almost stoichiometric.

Table 1. Sputtering deposition parameters - only power applied to silicon target was changed in thin films samples.

\begin{tabular}{ccccc}
\hline Sample & $\begin{array}{c}\text { Working Pressure } \\
{[\mathbf{m} \text { Torr] }}\end{array}$ & $\begin{array}{c}\text { Zr DC Power } \\
{\left[\mathbf{W} / \mathbf{c m}^{2}\right]}\end{array}$ & $\begin{array}{c}\text { Si RF Power } \\
{\left[\mathbf{W} / \mathbf{c m}^{2}\right]}\end{array}$ & Ar flux [sccm] \\
\hline ZrN & 3.0 & 6.0 & 0.0 & 19.0 \\
ZrSiN_1 & 3.0 & 6.0 & 1.2 & 19.0 \\
ZrSiN_2 & 3.0 & 6.0 & 2.2 & 19.0 \\
ZrSiN_3 & 3.0 & 6.0 & 3.7 & 2.0 \\
\hline
\end{tabular}


for others films is $11 \mathrm{~nm}$. A small peak at $54^{\circ}$ was found for all samples and is probably associated with $\mathrm{ZrO}_{2}$ or $\mathrm{ZrSiO}_{4}$ phases.

Reference pattern ICDD PDF 35-0753 presented in Figure 2 shows that the main peaks for $\mathrm{ZrN}$ are (111) and (200) orientations, with this last presenting an intensity of $70 \%$ compared with (111) peak. Comparing the ICDD pattern with the $\mathrm{ZrN}$ and $\mathrm{ZrSiN}$ coatings deposited on this work, it is clear the decreasing of (200) peak intensity, showing that there is a high fraction of (111) oriented grains when compared to others orientations, especially the (200) grains. It is important to note that as the silicon content is increased, it can be observed that $\mathrm{I}(200) / \mathrm{I}(111)$ ratio is increased from $14.2 \%$ to $18.9 \%$, showing that (200) grains growth during deposition is favored due the silicon content. These results can be better observed in Figure 3.

Grains with (200) orientation have the lowest surface energy, while (111) grains have the lowest deformation energy. Thin films deposited by sputtering have high defects concentration, which causes crystal lattice distortion and promotes the (111) preferred orientation due to deformation energy minimization ${ }^{20,21}$. Grains with (111) orientation grow in the normal direction to the film plane, which contributes to the formation of a columnar microstructure, while (200) grains grow in the parallel direction, having the potential to change the columnar morphology to a non columnar one ${ }^{22}$.

The silicon addition act as a nucleation center for $\mathrm{ZrN}$ grains, reducing the crystallite size and creating thermodynamic conditions to the (200) oriented grains. The (200) indicates that the system is minimizing the surface energy and it can be concluded that the amount of defects in the film is reduced, which can improve thin film properties and characteristics.

Figure 4 shows nanohardness results for $\mathrm{ZrN}$ and $\mathrm{ZrSiN}$ thin films. The $\mathrm{ZrN}$ hardness was determined in about $15.6 \mathrm{GPa}$, value consistent with literature. Samples $\mathrm{ZrSiN} \_1, \mathrm{ZrSiN} 2$ and $\mathrm{ZrSiN} 33$ had no significant variation in nanohardness. For ZrSiN_1 and ZrSiN_2 the Si addition in low concentration was not enough to change the structure and mechanical properties. But, for $\mathrm{ZrSiN} 3$ the highest I(200)/I(111) ratio contributes to hardness reduction and, on the other hand, the lowest crystallite size and the microstructure composed by $\mathrm{ZrN}$ and $\mathrm{Si}_{3} \mathrm{~N}_{4}$ phases contributes to increase this mechanichal propertie ${ }^{23}$. The global result is no significant impact in hardness for $\mathrm{ZrSiN} 3$ sample.

Young's modulus results (Figure 4) has similar trend as observed for hardness values and the same interpretations can be pointed out for this mechanichal propertie.

Figure 5 shows FEG-SEM of ZrSiN_2 thin film cross section with a non columnar structure. All ZrSiN coatings presented this same behavior. Silicon addition promoted a transition from a columnar morphology to a non columnar one as the Si content is increased. This microstructure is aligned

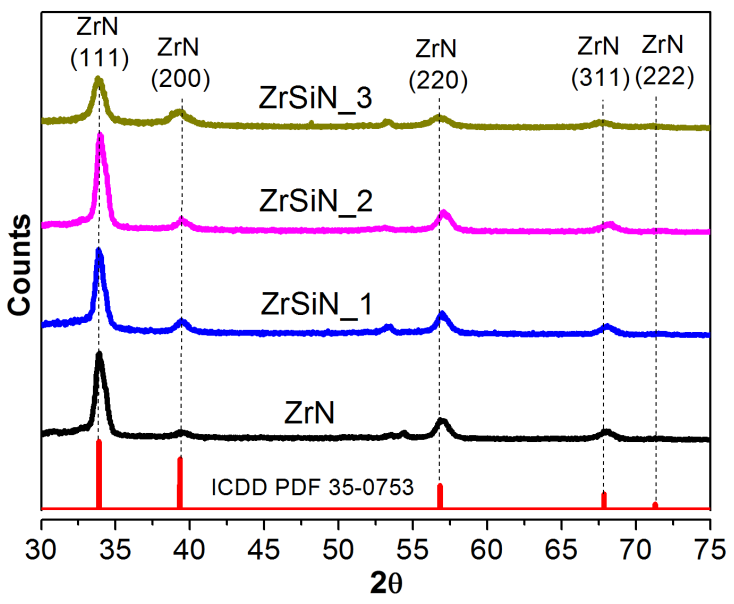

Figure 2. Grazing angle $\left(1^{\circ}\right) \mathrm{XRD}$ analysis - (111) peak intensity reduction and broadening for $\mathrm{ZrSiN} \_3$ sample. It can be verified the (111) preferred orientation for $\mathrm{ZrN}$ and $\mathrm{ZrSiN}$ thin films. The peaks intensities obtained from ICDD PDF 35-0753 are also presented.

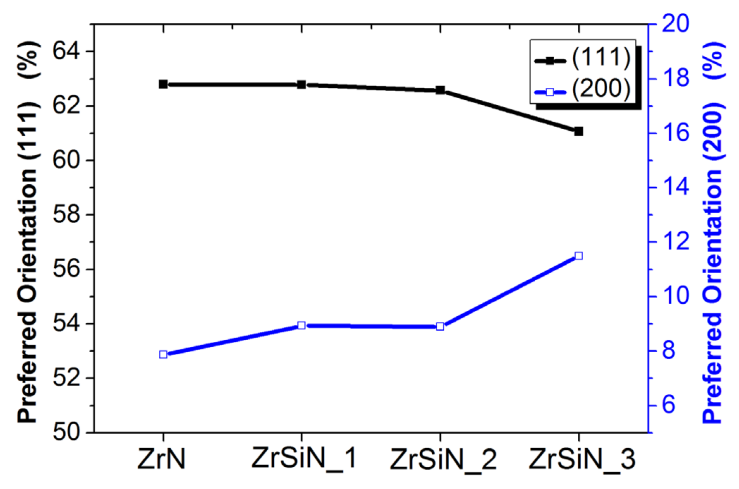

Figure 3. Preferred orientation obtained from GAXRD $1^{\circ}-\mathrm{I}(200) / \mathrm{I}(111)$ ratio is higher as $\mathrm{Si}$ content is increased.

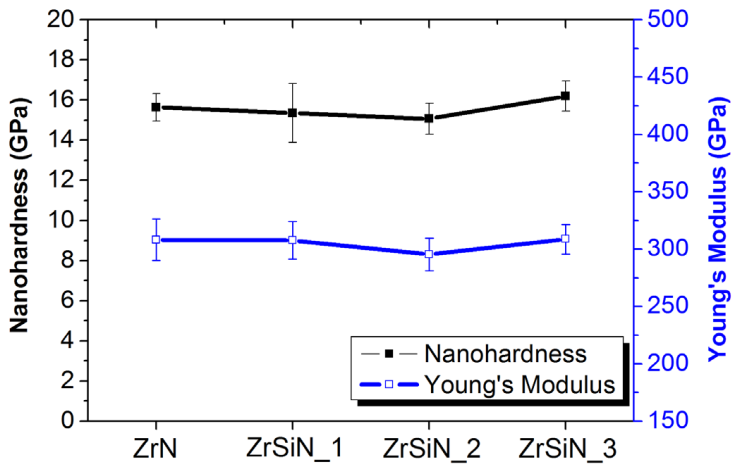

Figure 4. Nanohardness and Young's Modulus - it is verified no significant changes for all films deposited.

Table 2. RBS analysis to N, $\mathrm{Zr}$ and $\mathrm{Si}$ - chemichal concentrations and thin film thickness.

\begin{tabular}{cccccc}
\hline Sample & N [at. \%] & Zr [at. \%] & Si [at. \%] & Si / (Zr+Si) [\%] & Thickness [nm] \\
\hline ZrN & $48.5 \pm 0.6$ & $51.5 \pm 0.6$ & - & - & $57 \pm 9$ \\
ZrSiN_1 & $48.4 \pm 0.6$ & $48.4 \pm 0.6$ & $3.2 \pm 0.1$ & $6.2 \pm 0.3$ & $59 \pm 10$ \\
ZrSiN_2 & $49.4 \pm 0.7$ & $46.5 \pm 0.7$ & $4.1 \pm 0.1$ & $8.0 \pm 0.2$ & $58 \pm 10$ \\
ZrSiN_3 & $48.9 \pm 0.8$ & $43.5 \pm 0.8$ & $7.6 \pm 0.1$ & $15.0 \pm 0.2$ & $68 \pm 9$ \\
\hline
\end{tabular}




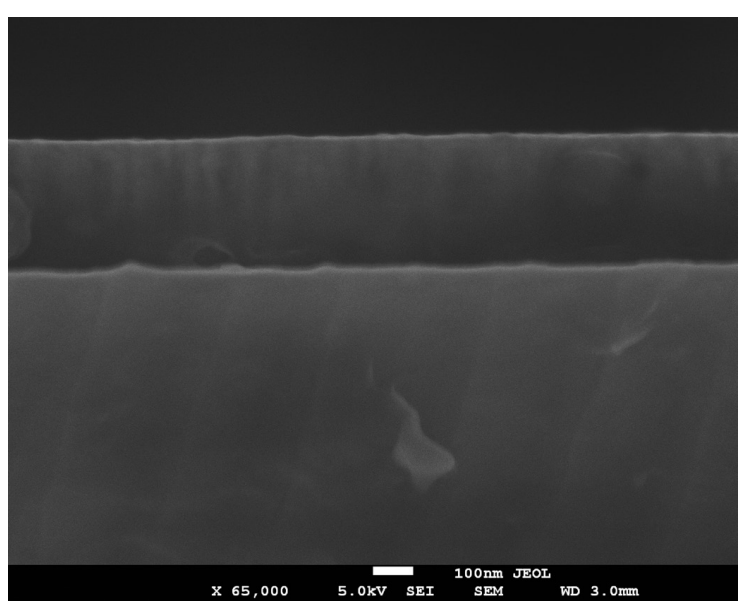

Figure 5. FEG-SEM image for $\mathrm{ZrSiN} \_2$ - it can be observed a morphology composed by non columnar structure.

with GAXRD results, confirming the Si potential to modify $\mathrm{ZrN}$ morphology by blocking the columnar structure growth. In other words, silicon atoms restricts the columnar growth due to an increase in $\mathrm{ZrN}$ grain nucleation rate, inhibiting the (111) orientation and favoring the (200) orientation.

It can be also verified that the thin films observed by FEG-SEM are homogeneous and have apparently good adhesion.

\section{Conclusions}

$\mathrm{ZrN}$ and $\mathrm{ZrSiN}$ were successively deposited by reactive magnetron sputtering. RBS analysis show $\mathrm{ZrN}$ coatings with stoichiometric near to $1: 1$ and the $\mathrm{Si} /(\mathrm{Zr}+\mathrm{Si})$ ratio of $\mathrm{ZrSiN}$

\section{References}

1. Musil J. Hard and superhard nanocomposite coatings. Surface and Coatings Technology. 2000; 125(1-3):322-330. http:// dx.doi.org/10.1016/S0257-8972(99)00586-1.

2. Benkahoul M, Sandu CS, Tabet N, Parlinska-Wojtan M, Karimi A and Lévy F. Effect of Si incorporation on the properties of niobium nitride films deposited by DC reactive magnetron sputtering. Surface and Coatings Technology. 2004; 188189:435-439. http://dx.doi.org/10.1016/j.surfcoat.2004.08.048.

3. Veprek S and Veprek-Heijman MGJ. Industrial applications of superhard nanocomposite coatings. Surface and Coatings Technology. 2008; 202(21):5063-5073. http://dx.doi.org/10.1016/j. surfcoat.2008.05.038.

4. Abadias G, Michel A, Tromas C, Jaouen C and Dub SN. Stress, interfacial effects and mechanical properties of nanoscale multilayered coatings. Surface and Coatings Technology. 2007; 202(4-7):844-853. http://dx.doi.org/10.1016/j.surfcoat.2007.05.068.

5. Lee $J$ and Yang G. Preparation of TiAlN/ZrN and TiCrN/ $\mathrm{ZrN}$ multilayers by RF magnetron sputtering. Transactions of Nonferrous Metals Society of China. 2009; 19(4):795-799. http://dx.doi.org/10.1016/S1003-6326(08)60352-0.

6. Ma S, Prochazka J, Karvankova P, Ma Q, Niu X, Wang X, et al. Comparative study of the tribological behavior of superhard nanocomposite coatings nc-TiN/a-Si3N4 with TiN. Surface and Coatings Technology. 2005; 194(1):143-148. http://dx.doi. org/10.1016/j.surfcoat.2004.05.007. coatings were determined as $6.2 \%, 8.0 \%$ and $15.0 \%$ when applied 1.2, 2.2 and $3.7 \mathrm{~W} / \mathrm{cm}^{2}$ at $\mathrm{Si}$ target, respectively. All coatings presented hafnium originated from zirconium target.

GAXRD patterns show a (111) peak broadening and intensity reduction for sample $\mathrm{ZrSiN} \_3$, but maintaining the preferred orientation (111). The crystallite size calculated by Scherrer pointed out that silicon addition creates a nanocomposite structure.

All thin films present a high fraction of (111) oriented grains, however it is observed an increase in I(200)/I(111) ratio in function of silicon content. Silicon addition creates thermodynamic conditions to deposit (200) oriented grains, which causes a reduction in films defects concentration.

Nanohardness analysis indicated no significant modification in hardness between $\mathrm{ZrN}$ and $\mathrm{ZrSiN}$ coatings. But, ZrSiN_3 sample has a set of characteristics that justifies the maintainability of its nanohardness (I(200)/I(111) ratio increase, crystallite size reduction and microstructure composed by two phases). Young's modulus have the same behaviour observed for nanohardness analyses.

FEG-SEM results show $\mathrm{ZrSiN}$ thin films with a non columnar structure. Silicon addition blocks the columnar growth due to the favorable conditions to (200) orientation. Increasing the $\mathrm{Si}$ content in $\mathrm{ZrN}$ thin films promotes a transition from a columnar to a non columnar structure.

\section{Acknowledgements}

The author would like to thank PETROBRAS S.A. for the opportunity to develop this work, which is inserted on PETROBRAS Human Resources Development Program (PDRH), and also FAPITEC for financial support.

7. Veprek S, Veprek-Heijman MGJ, Karvankova P and Prochazka J Different approaches to superhard coatings and nanocomposites. Thin Solid Films. 2005; 476(1):1-29. http://dx.doi.org/10.1016/j. tsf.2004.10.053.

8. Veprek S and Veprek-Heijman MGJ. Limits to the preparation of superhard nanocomposites: impurities, deposition and annealing temperature. Thin Solid Films. 2012; 522:274-282. http://dx.doi.org/10.1016/j.tsf.2012.08.048.

9. Veprek S, Mannling HD, Karvánková P and Procházka J. The issue of the reproducibility of deposition of superhard nanocomposites with hardness of $\geq 50 \mathrm{GPa}$. Surface and Coatings Technology. 2006; 200(12-13):3876-3885. http:// dx.doi.org/10.1016/j.surfcoat.2004.11.023.

10. Sandu CS, Sanjinés R and Medjani F. Control of morphology ( $\mathrm{ZrN}$ crystallite size and SiNx layer thickness) in $\mathrm{Zr}-\mathrm{Si}-\mathrm{N}$ nanocomposite thin films. Surface and Coatings Technology. 2008; 202(11):2278-2281. http://dx.doi.org/10.1016/j. surfcoat.2007.09.003.

11. Pilloud D, Pierson JF and Takadoum J. Structure and tribological properties of reactively Zr-Si-N films. Thin Solid Films. 2006; 496(2):445-449. http://dx.doi.org/10.1016/j.tsf.2005.09.062.

12. Sandu CS, Harada S, Sanjinés R and Cavaleiro A. A unique approach to reveal the nanocomposite nc-MN/SiN-layer architecture of thin films via electrical measurements. Surface and Coatings Technology. 2010; 204(12-13):1907-1913. http:// dx.doi.org/10.1016/j.surfcoat.2009.11.045. 
13. Sandu CS, Sanjinés R, Benkahoul M, Medjani M and Lévy F. Formation of composite ternary thin films by magnetron sputtering co-deposition. Surface and Coatings Technology. 2006; 201(7):4083-4089. http://dx.doi.org/10.1016/j. surfcoat.2006.08.100.

14. Sandu CS, Medjani F, Sanjinés R, Karimi A and Lévy F. Structure, morphology and electrical properties of sputtered $\mathrm{Zr}-\mathrm{Si}-\mathrm{N}$ thin films: from solid solution to nanocomposite. Surface and Coatings Technology. 2006; 201(7):4219-4223. http://dx.doi.org/10.1016/j.surfcoat.2006.08.002.

15. Sandu CS, Benkahoul M, Sanjinés R and Lévy F. Model for the evolution of $\mathrm{Nb}-\mathrm{Si}-\mathrm{N}$ thin films as a function of $\mathrm{Si}$ content relating the nanostructure to electrical and mechanical properties. Surface and Coatings Technology. 2006; 201(6):2897-2903. http://dx.doi.org/10.1016/j.surfcoat.2006.06.003.

16. Sandu CS, Cusnir N, Oezer D, Sanjinés R and Patscheider J. Influence of bias voltage on the microstructure and physical properties of magnetron sputtered $\mathrm{Zr}-\mathrm{Si}-\mathrm{N}$ nanocomposite thin films. Surface and Coatings Technology. 2009; 204(6-7):969972. http://dx.doi.org/10.1016/j.surfcoat.2009.06.042.

17. Patscheider J, Zehnder T and Diserens M. Structure-performance relations in nanocomposite coatings. Surface and Coatings Technology. 2001; 146-147:201-208. http://dx.doi.org/10.1016/ S0257-8972(01)01389-5.
18. Lamni R, Martinez E, Springer SG, Sanjines R, Schmid PE and Levy F. Optical and electronic properties of magnetron sputtered ZrNx thin films. Thin Solid Films. 2004; 447-448:316-321. http://dx.doi.org/10.1016/S0040-6090(03)01109-X.

19. Musil J. Hard nanocomposite coatings: thermal stability, oxidation resistance and toughness. Surface and Coatings Technology. 2012; 207:50-65. http://dx.doi.org/10.1016/j. surfcoat.2012.05.073.

20. Abadias G. Stress and preferred orientation in nitride-based PVD coatings. Surface and Coatings Technology. 2008; 202(11):22232235. http://dx.doi.org/10.1016/j.surfcoat.2007.08.029.

21. Goldfarb I, Pelleg J, Zevin L and Croitoru N. Lattice distortion in thin films of IVB metal (Ti, Zr, Hf) Nitrides. Thin Solid Films. 1991; 200(1):117-127. http://dx.doi.org/10.1016/00406090(91)90034-U.

22. Banerjee R, Chandra R and Ayyub P. Influence of the sputtering gas on the preferred orientation of nanocrystalline titanium nitride thin films. Thin Solid Films. 2002; 405(1-2):64-72. http://dx.doi.org/10.1016/S0040-6090(01)01705-9.

23. Procházka J, Karvánková P, Veprek-Heijman MGJ and Veprek $\mathrm{S}$. Conditions required for achieving superhardness of $\geq 45$ $\mathrm{GPa}$ in nc-TiN/a-Si3N4 nanocomposites. Materials Science and Engineering A. 2004; 384(1-2):102-116. http://dx.doi. org/10.1016/j.msea.2004.05.046. 